\title{
A SECRETORY DEPRESSANT IN GASTRIC JUICE OF PATIENTS WITH PERNICIOUS ANEMIA ${ }^{1}$
}

\author{
BY ALEXANDER BRUNSCHWIG, JOHN VAN PROHASKA, T. HOWARD \\ CLARKE, 2 AND ERNESTINE KANDEL
}

\begin{abstract}
(From the Departments of Surgery and Medicine, and the Douglas Smith Foundation,
\end{abstract} The University of Chicago, Chicago)

(Received for publication January 30, 1939)

It has been generally inferred that the achlorhydria and marked gastric hyposecretion, which almost invariably accompany pernicious anemia, are the result of a marked atrophy of the gastric mucosa, the latter change being a part of the classical manifestations of the disease. Achlorhydria of course is not pathognomonic of any specific condition but is observed accompanying a variety of local and systemic diseases, is observed not infrequently in old age and in young and middle aged subjects presenting no other apparent abnormalities. The question of achlorhydria is directly associated with the question of the mechanism of free acid secretion in normal gastric juice. No adequate explanation of this latter mechanism has as yet been made. The commonly accepted theory is that $\mathrm{HCl}$ is secreted by the gastric gland cells (parietal cells) in some combined form and that it is not liberated as free $\mathrm{HCl}$ until it reaches the foveolae of the glands. The manner of this liberation is likewise not understood. Thus, several possibilities exist to explain any given instance of achlorhydria. There may be a congenital defect in the secretory mechanism of the parietal cells, an atrophy of the fundic glands due to age, or to a variety of pathological conditions, or there may be some disturbance in the mechanism for liberation of the bound $\mathrm{HCl}$ in the foveolae.

A normal physiological mechanism for the inhibition of gastric secretion has been known for many years, starting with the observation that a fatty meal inhibited such secretion as well as gas-

1 These observations are incidental to an investigation on the effects of extracts of human gastric cancer on the gastric secretion in dogs which is being carried out under grants from the International Cancer Research Foundation, Philadelphia, Pennsylvania, and the National Advisory Council on Cancer, of the U. S. Public Health Service, Washington, D. C.

2 Research Assistant, International Cancer Research Foundation Fund. tric motility. This question was studied in greater detail recently by Ivy and his associates (1). Kosaka and Lim (2) in 1930 showed that this inhibition was accomplished by the production of a hormone (chalone) in the mucosa of the upper small bowel when this was in contact with fat (olive oil). This hormone, which they call "enterogastrone," when injected intravenously in dogs induces a marked inhibition of gastric secretion both as to volume and acid content.

The possibility that achlorhydria in pernicious anemia might be in some way associated with a factor other than simple atrophy of the gastric mucosa does not seem to have been previously investigated. It may be that some substance is formed incident to the development of the disease, which, acting at least in the foveolar portions of the gastric glands or upon the parietal cells themselves, leads to inhibition of secretion of $\mathrm{HCl}$ and its liberation as free $\mathrm{HCl}$, but this possibility apparently has not received attention. In order to investigate this question it was decided to inject gastric juice from pernicious anemia patients intravenously into dogs with gastric pouches and to observe whether any inhibitory action would result upon the secretion from the pouches stimulated by feeding the animals.

No previous observations have been found in the literature upon the effects of gastric juice itself upon gastric secretion, when the former was injected intravenously. Such a study, as regards the stomach at least, would appear justifiable on the principle that one method of studying the pathological physiology of a secreting tissue is to observe the properties of its pathological secretions.

\section{METHODS}

Subtotal gastric pouches were made in some dogs by uniting the lower one-half of the pylorus to the cardiac portion with closure of the isolated 
central portion and cannulation of it with a Dragstedt gold plated cannula which was brought through a stab wound in the abdominal wall. Most of the nerves and arteries to such pouches were preserved. In others, Heidenhain pouches were made and cannulated as just described. Secretion from the cannula was collected in glass Soxlet flasks attached about the body of the animal by cords (See Figure 1).
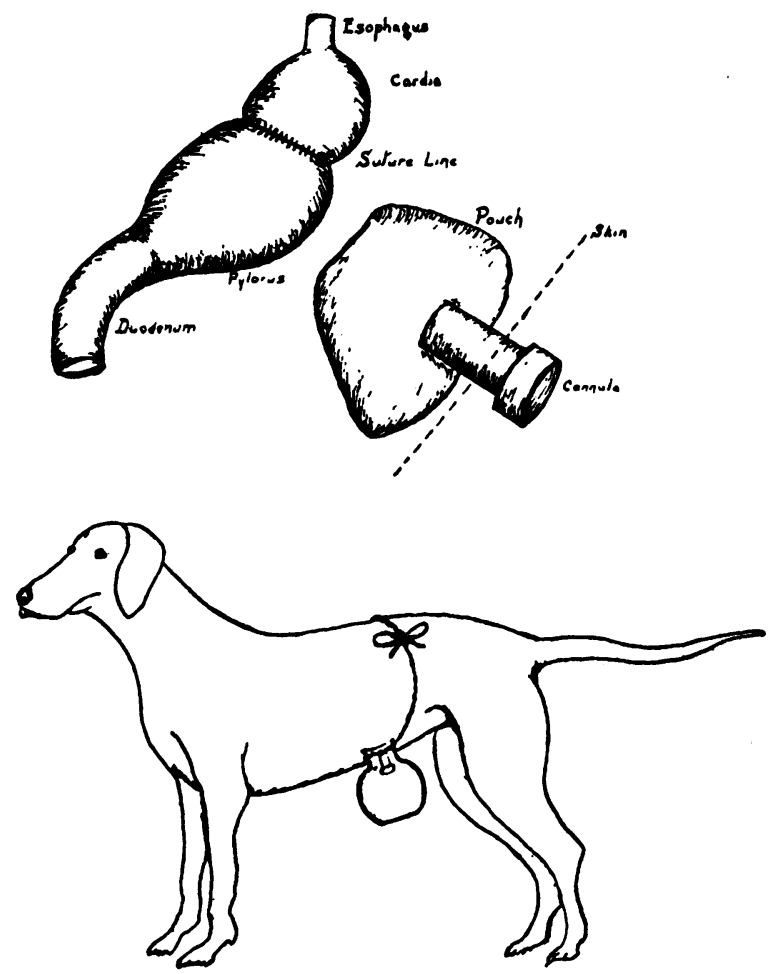

Fig. 1. Showing Method of Collection of Gastric Juice from Dog with Subtotal Gastric Pouch

Above, schematic diagram of operation for making gastric pouch. The mid-portion of the stomach is isolated but nerves and vessels to this portion are kept intact. The cardia is anastomosed to the lower one-half to one-third of the pylorus by 2 rows of continuous sutures. The pouch is cannulated through a stab wound in the anterior abdominal wall.

The writers are aware of the criticisms which might be made concerning the secretory activity of gastric pouches, especially of the size of the Heidenhain pouch, namely, that such pouches may not always secrete when the stomach itself is actively secreting. In the following experiments no dog was employed in whom adequate control experiments had not been performed to demonstrate the reliability of the secretory mechanism of the pouch when the animals were fed.

In this series of experiments interest was centered upon factors inhibiting gastric secretion. Thus at the beginning of the experiment the dogs were fed (forcefully if necessary) cooked and raw meat, or lung stew and were permitted free movement upon a large table with access to limited quantities of water. When active secretion was established in 30 to 60 minutes, the human gastric juice to be tested (previously neutralized with $1 / 10 \mathrm{~N} \mathrm{NaOH}$ if necessary) was injected intravenously in an extremity and the effect noted upon the pouch secretion. The pouch juice was collected at 10-minute intervals and titrated with Toepfer's reagent and phenolphthalein for free and combined acid, the results being expressed in "clinical units." One feeding, i.e., a mass of food totalling approximately 6 to $8 \mathrm{~cm}$. in diameter given in smaller boli was sufficient to insure active secretion for over an hour in most dogs. However, to insure adequate stimulation, especially where the experiments were critical, voluntary or forced feedings were given at 20 to 40-minute intervals throughout the experiment. Control experiments showed that once active secretion was established vomiting of all food taken did not result in a sudden arrest of secretion from the pouch but that this often continued for approximately one hour or more if the animal was not refed. In critical experiments, however, the animal was refed from 5 to 10 minutes after any vomiting to insure continued food stimulation of the stomach.

The gastric juices were obtained by tube aspirations from patients who had received subcutaneous injections of histamine, according to the usual technique of a histamine test for gastric secretion. After centrifugation they were neutralized with $1 / 10 \mathrm{~N} \mathrm{NaOH}$ when necessary, the added volume being taken into consideration when injections were made in the animals. These injections were arbitrarily fixed at $1 \mathrm{cc}$. of gastric juice per kilogram of the animals' weight. When possible, juices were injected within a few hours after recovery, otherwise they were kept on ice.

The patients with pernicious anemia were from the Hematology Clinic of the Department of Medicine and were clinically and hematologically typical of pernicious anemia. Hemoglobin deter- 
minations were made by the Newcomer hemoglobinometer, and blood counts and cell volumes by the standard methods. All cases showed a macrocytic hyperchromic anemia when first seen. Routine gastro-intestinal $\mathrm{x}$-rays were made in all cases to rule out other gastro-intestinal diseases. Histamine tests of gastric secretion showed no free $\mathrm{HCl}$ on various occasions. Reticulocyte response to liver therapy was prompt. The control patients were from the various hospital services, all being sufficiently ill to have been hospitalized (i.e., the control group was not made up of normal individuals).

\section{RESULTS}

$A$. Preliminary control experiments, 12 in number, were performed in which the neutralized gastric juice from the pouch of a dog fed lean meat was injected intravenously into that dog. No effects were observed upon secretion from the pouch stimulated by feeding. Similar negative results were obtained by injection of neutralized gastric juice from other dogs' pouches.

The effect of temperature. In 1932 Vanzant and Snell (3) observed inhibition of gastric secretion in dogs whose temperature was suddenly elevated by injection of bacterial protein. It was observed by us that a rise in temperature over 30 minutes to 1 or 2 hours to above $40.5^{\circ} \mathrm{C}$. (rectal) resulted in a rather sudden and marked depression in secretion of gastric juice and an achlorhydria. Thus rectal temperature readings were taken at intervals of 10 to 30 minutes throughout the experiments and when they rose above $40.5^{\circ}$ to $40.6^{\circ}$ the experiment was not accepted. The animals were then "vaccinated" by repeated daily injections against the fever producing elements in the juice. After some time some of the animals became "temperature resistant" and continued to secrete acid juice in adequate quantities while having temperatures as high as $42^{\circ} \mathrm{C}$. Obviously, once such a temperature resistance developed, as shown by control experiments, results observed during any temperatures up to this point were considered valid in these animals.

In the literature on experimental studies of substances inhibiting gastric secretion no attention seems to have been paid to sudden rises in temperature due to such injections.
$B$. The ntravenous injection of achlorhydric gastric juite from patients with pernicious anemia.

The results observed upon stimulated pouch secretions are given in Table $I$ and Figure 2. The result recorded opposite the abbreviated name of the animal employed indicates one acceptable experiment.

The secretory inhibition was manifested in most of the positive experiments after a latent period of 20 to 60 minutes following injection, but in some cases it was as long as 90 to 120 minutes.

Cases 1 to 5 inclusive were of long standing and had had blood counts that were normal or above normal, with slight lapses during intercurrent infections, for a number of years.

TABLE I

Summary of experiments with gastric juice from patients with pernicious anemia

\begin{tabular}{|c|c|c|c|}
\hline $\begin{array}{c}\text { Patient and } \\
\text { history number }\end{array}$ & $\begin{array}{c}\text { Maxi- } \\
\text { mum free } \\
\mathrm{HCl} \text { in } \\
\text { gastric } \\
\text { juice. } \\
\text { Hista- } \\
\text { mine test }\end{array}$ & $\begin{array}{c}\text { Inhibition of } \\
\text { secretion from } \\
\text { stimulated pouch * }\end{array}$ & $\begin{array}{l}\text { Effect of juice } \\
\text { boiled for } \\
10 \text { minutes }\end{array}$ \\
\hline 1. Jurg & 0 & $\underset{\text { Dog Trix }}{+}+$ & Dog Nap - \\
\hline 2. $\operatorname{Sim}_{(23156)}$ & 0 & Bud. + & Bud. - \\
\hline $\begin{array}{l}\text { 3. Thom } \\
(78289)\end{array}$ & 0 & $\begin{array}{ll}\text { Trix } & +++t \\
\text { Trix } & - \\
\text { Kg. } & +t+ \\
\text { Nap } & +\end{array}$ & \\
\hline $\begin{array}{l}\text { 4. } \text { Mol } \\
(132207)\end{array}$ & 0 & Kg. + & Kg. - \\
\hline $\begin{array}{l}\text { 5. Pir. } \\
\text { (128721) }\end{array}$ & 0 & $\begin{array}{l}\text { Bud } \\
\text { Bud } \\
\text { Bud }\end{array}$ & Bud - \\
\hline 6. Sul. & 0 & $\begin{array}{l}\text { Kg. } \quad \\
\text { Fid. } \quad \\
\text { May }+ \\
\text { May } \\
\text { Nap. - }\end{array}$ & \\
\hline 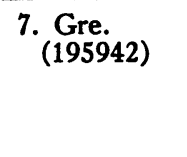 & 0 & $\begin{array}{l}\text { Trix }+t++ \\
\text { Kg. } \quad- \\
\text { May } t+ \\
\text { May } t++ \\
\text { Nap. } \quad\end{array}$ & May - \\
\hline $\begin{array}{l}\text { 8. Hans } \\
(198755)\end{array}$ & 0 & $\begin{array}{l}\text { Mon. - } \\
\text { Mon. - }\end{array}$ & \\
\hline $\begin{array}{l}\text { 9. Tub. } \\
\text { (206430) }\end{array}$ & 0 & $\begin{array}{l}\text { Kg. } \quad++++ \\
\text { Nap. }++\end{array}$ & $\mathrm{Kg} \cdot-$ \\
\hline $\begin{array}{l}\text { 10. Conl } \\
(196359)\end{array}$ & 0 & $\begin{array}{l}\text { Mon. } t+t \\
\text { Nap. }-\bar{t} \\
\text { Sam. } t+t+\end{array}$ & Mon.- \\
\hline
\end{tabular}


TABLE I-Continued

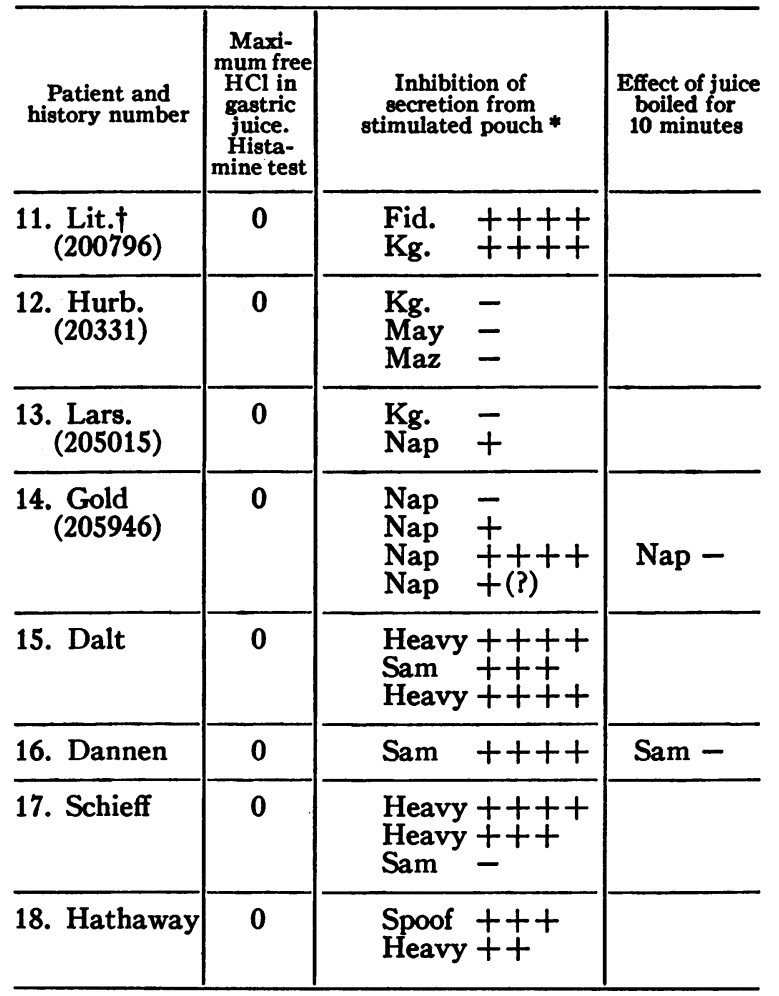

† Patient also had carcinoma of the stomach.

*- = No effect on secretion of stimulated pouch.

$+=$ Marked reduction in volume of secretion per 10-minute period to 4 drops or less for at least 2 such periods and with persistence of free acid or reduction in free acid titer to 25 or less clinical units providing the secreted juice exhibited at least 60 or 70 clinical units before injection.

$++=$ Reduction in volume of secretion with actual achlorhydria for at least 10 minutes but not more than 30 minutes.

$+++=$ Reduction in volume of secretion with actual achlorhydria for 30 to 60 minutes.

$++++=$ Reduction in volume of secretion with actual achlorhydria for 60 minutes or longer.

Cases 6 to 11 inclusive had had several years of irregular therapy before being seen in this clinic, and when gastric juices were aspirated for these experiments the red cell counts were low. Case 11 also had a small carcinoma of the pylorus which was resected.

Cases 12 to 14 inclusive were admitted to the hospital with very low counts and had had no previous liver therapy. Case 13 secreted very little juice in spite of histamine injection. The negative response observed in $\mathrm{Dog} \mathrm{Kg}$. was obtained when the patient was still very weak and yielded only enough juice to equal 80 per cent ( $3.5 \mathrm{cc}$.) of the regular dose for the dog. The one plus result observed in Dog Nap. was obtained some time later when the patient had improved clinically but was still unable to yield more than 7.5 cc. (about half the necessary dose for this $\mathrm{dog}$ ) of juice during 80 minutes following histamine injection. A third attempt after further clinical improvement yielded only $1 \mathrm{cc}$. of gastric juice, insufficient for an experiment. Case 14 was also very weak on admission and the first aspiration, obtained with difficulty, gave the negative result. The subsequent aspirations which gave positive results were made when there had been improvement in the blood and general condition.

Case 15 had a walnut-sized benign papilloma of the stomach which was successfully excised.

Case 16 had had a radical gastrectomy 5 years previously for carcinoma and when seen at the time of this experiment had typical pernicious anemia without evidence of recurrent carcinoma.

Case 18 also presented hyperthyroidism which was successfully treated by operation.

It is to be noted that the dogs vary widely in the quantity of secretion produced by the pouch depending. upon its size and size of the dog. Also, dogs vary in their response to factors depressing secretion, some "weak secretors" responded markedly to the depressing factor, other "strong secretors" were not as easily rendered achlorhydric, and when this did develop it was relatively less prolonged. Furthermore, the dogs may be strong secretors on some days and weaker secretors on other days. These characteristics became evident during a number of experiments upon each dog. Marked variations in volume of secretion such as a drop from $3 \mathrm{cc}$. or more to 0.4 or 0.5 cc. per 10-minute period following injection were ignored. Furthermore, variations in the titer of free acid of the order of 50 or 60 or more clinical units were also ignored where such titers did not fall below 30 units. (For example, a transitory drop in titer of free acid from 120 to 40 or 50 after injection of a pernicious anemia gastric juice was still considered a negative response.)

An endeavor was made to obtain more than one acceptable experiment with each sample. However, this was not always possible as much of a sample might be used in experiments that could not be accepted because the achlorhydria was accompanied by hyperthermia, and so additional 


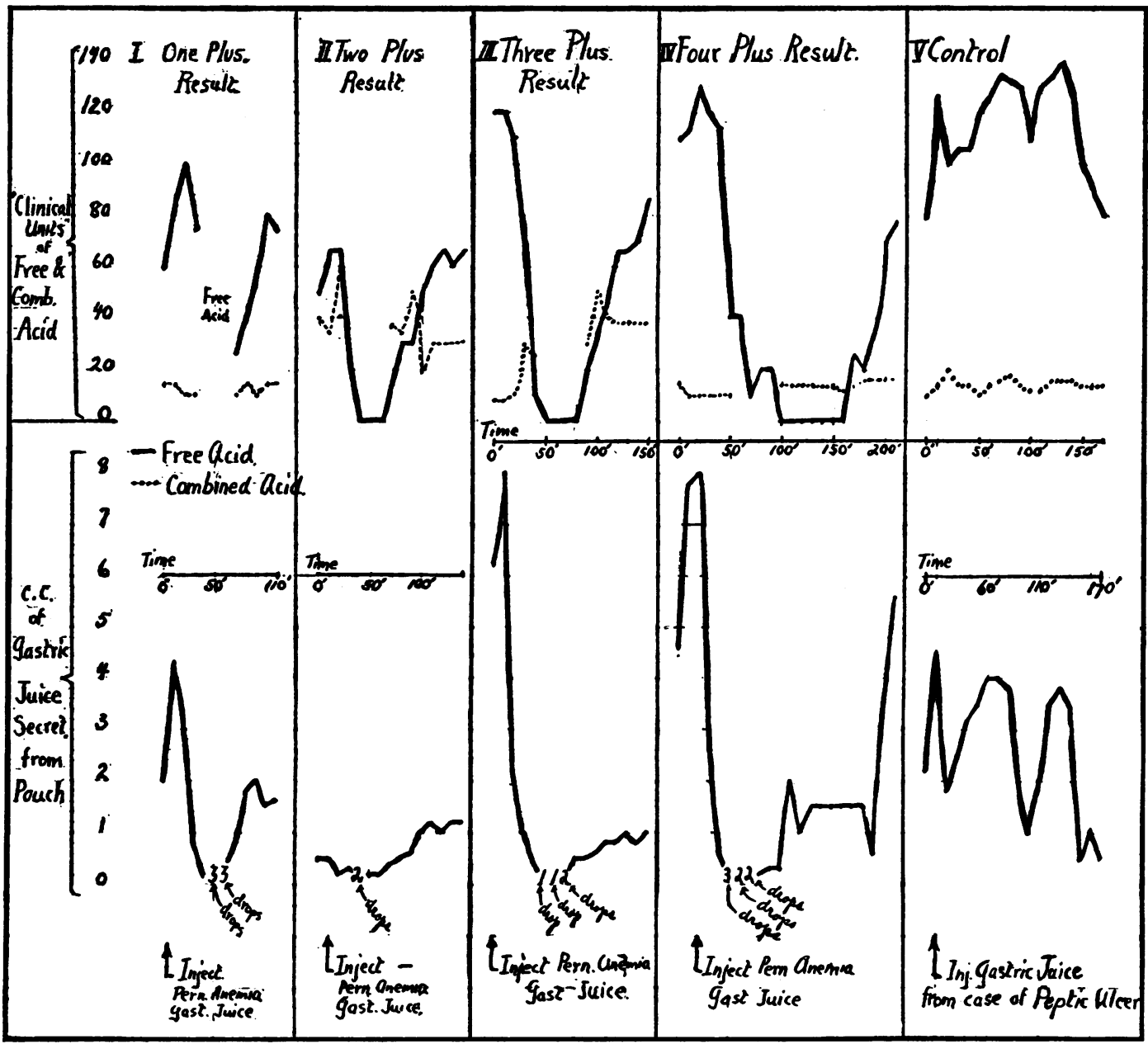

Fig. 2. Condensed Grapes to Show Effects of Injection of Gastric Juices from Patients with Pernictous Anemia on Secretions from Stimulated Gastric Pouches in Dogs

I. A one plus result, the volume of secretion is reduced to $0.2 \mathrm{cc} .3$ and 3 drops respectively for each of 310 -minute periods. Free acid always present.

II. A two plus reaction, reduction in volume of secretion with achlorhydria for 30 minutes.

III. A three plus reaction, achlorhydria for $\mathbf{4 0}$ minutes with reduction in volume of secretion.

IV. A four plus reaction, achlorhydria for 70 minutes with reduction in volume of secretion.

V. A negative response in a control experiment in which neutralized gastric juice from a patient with peptic ulcer was injected.

quantities of the sample had to be employed for immunization of the dog by repeated small injections against the fever producing substances in the juice.

While it was impractical to carry out all positive and negative experiments in the pernicious anemia and in the control group in each dog, all of the dogs in the pernicious anemia group of experiments were also employed in several of the control experiments.
Boiling the juices for 10 minutes inactivated the gastric secretory depressant if the latter was present in the unboiled sample.

C. Control experiments with human gastric juice. Gastric juices from 34 patients not suffering from pernicious anemia or malignant neoplasm were also obtained according to the usual procedure for the histamine test for gastric secretion and these were injected (after neutralization if 
necessary) into the dogs as controls for the experiments in Group B. The results are summarized in Table II. In 6 out of 34 instances inhibition of pouch secretion was noted (Cases 1, 13, $19,26,30,32$ ) and, as in the previous group, except for one instance, boiling these "positive" samples resulted in inactivation of the secretory inhibitor. Fourteen of the control group yielded achlorhydric gastric juices following histamine injection and, of these, 2 samples afforded positive experiments. Cases 27 and 28 were artificial achlorhydrias having been produced some time previously by radiation of the stomach with $\mathbf{x}$-ray in the treatment of peptic ulcer.

\section{DISCUSSION}

Samples of gastric juices from 16 of 18 patients with pernicious anemia, 89 per cent of the samples,

TABLE II

Gastric juices with normal or high acid from patients not presenting malignant neoplasms or pernicious anemia

\begin{tabular}{|c|c|c|c|c|c|}
\hline \multirow{2}{*}{\begin{tabular}{c|} 
Patient \\
1. K.......
\end{tabular}} & \multirow{2}{*}{$\begin{array}{c}\text { Diagnosis } \\
\begin{array}{c}\text { Acuto cellulitis of } \\
\text { legs }\end{array}\end{array}$} & \multirow{2}{*}{ 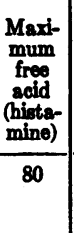 } & \multicolumn{2}{|c|}{ Dog and result } & \multirow[t]{2}{*}{ Boiled } \\
\hline & & & $\begin{array}{l}\text { Tyx } \\
\text { Bud } \\
\text { Bid. }\end{array}$ & & \\
\hline 2. Feh...... & Miliary tuberoulodia & 75 & $\underset{\text { Min }}{\text { Min }}$ & & \\
\hline 8. Thomp. & $\begin{array}{l}\text { Hypertrophio gas. } \\
\text { tritis }\end{array}$ & 45 & $\begin{array}{l}\text { Nap } \\
\mathbf{K} \text { g. }\end{array}$ & $\overline{-}$ & \\
\hline 4. Ojal..... & Peptic ulcer & 40 & $\begin{array}{l}\text { Nap } \\
\text { Nap }\end{array}$ & $\overline{-}$ & \\
\hline B. Stud..... & Peptic uloer & 70 & Tr. & - & \\
\hline 6. Gorm.... & Peptic ulcer & 66 & Tr. & - & \\
\hline 7. Bur....... & Peptlo ulcer & 40 & Min. & & \\
\hline 8. Wurth... & Peptic uloer & 80 & $\mathbf{K}_{\mathbf{g}}$ & - & \\
\hline 9. Wolff.... & Peptio ulcer & 100 & $\begin{array}{l}\text { Nap } \\
\text { Nap }\end{array}$ & $\overline{-}$ & \\
\hline 10. Bergst... & Peptic ulcer & 68 & $\begin{array}{l}\text { Nap } \\
\mathbf{K g} .\end{array}$ & $\overline{-}$ & \\
\hline 11. Savage.. & $\begin{array}{l}\text { Tubercular lymph- } \\
\text { adenitis }\end{array}$ & 20 & Nap & - & \\
\hline 12. Fotter... & Secondary anemis & 75 & Nap & - & \\
\hline 13. O'Dall... & $\begin{array}{l}\text { Cholecystitis } \\
\text { 2d specimen }\end{array}$ & $\begin{array}{l}80 \\
80 \\
\end{array}$ & $\begin{array}{l}\text { Heavy } \\
\text { Eva } \\
\text { Dan } \\
\text { Heavy } \\
\end{array}$ & $\begin{array}{l}+t+t \\
\bar{t} \\
\end{array}$ & Heavy $t+t+$ \\
\hline 14. Benetps. & Lues & 65 & $\begin{array}{l}\text { Heavy } \\
\text { Dan }\end{array}$ & $\overline{-}$ & \\
\hline 15. Shulman. & Hypothyroidiom & 76 & $\begin{array}{l}\text { Heavy } \\
\text { Bust. }\end{array}$ & $\overline{-}$ & \\
\hline 16. Johngon. & Cholecystitis & 60 & $\begin{array}{l}\text { Heavy } \\
\text { Dan }\end{array}$ & $\overline{-}$ & \\
\hline
\end{tabular}

TABLE II-Continued

\begin{tabular}{|c|c|c|c|c|c|}
\hline Patient & Diagnosis & $\begin{array}{l}\text { Maxi- } \\
\text { mum } \\
\text { free } \\
\text { acid } \\
\text { (hista- } \\
\text { mine) }\end{array}$ & Dog and & I result & Boiled \\
\hline 17. De Chat. & Pancreatitis & 65 & $\begin{array}{l}\text { Dan } \\
\text { Bust }\end{array}$ & & \\
\hline 18. Furman . & Peptio uloer & 70 & Heavy - & & \\
\hline 19. Booga... & Cholecystitis & 75 & $\begin{array}{l}\text { Droopy } \\
\text { Spoof } \\
\text { Lis. }\end{array}$ & & \\
\hline 20. Barry... & Cholecystitis & 15 & Jok - & - & \\
\hline 21. Furl..... & Cholecystitis & 0 & Monk - & - & \\
\hline 22. Rosp.... & Senility & 0 & K8. & - & \\
\hline 23. $\mathrm{O}^{\prime} \mathrm{H} . . .$. & Oeteoporodis & 0 & K8. - & - & \\
\hline 24. Finsl..... & Chronio nephritis & $\mathbf{0}$ & $\begin{array}{l}\text { Nap } \\
\mathbf{K}_{\mathbf{g}} .\end{array}$ & - & \\
\hline 25. Rhode... & Peptic ulcer & $\mathbf{0}$ & $\mathrm{K}_{\mathrm{g} .}$ & - & \\
\hline 26. Chid..... & Peptic ulcer......... & 0 & $\begin{array}{l}\text { Min } \\
\text { Min }\end{array}$ & + & May - \\
\hline 27. Fred..... & X-ray achlorhydria & 0 & Sk $\quad-$ & - & \\
\hline 28. Bath.... & X-ray achlorhydria & 0 & Monk - & - & \\
\hline 29. Geath.... & Cholecystitis & 0 & $\begin{array}{l}\text { Eva } \\
\text { Heany } \\
\text { Dan }\end{array}$ & $\bar{z}$ & \\
\hline 30. Murry... & Cirrhosis & 0 & $\begin{array}{l}\text { Dan } \\
\text { Heavy } f\end{array}$ & ++++ & Dan - \\
\hline 31. Kinoski.. & Peptic ulcer & 0 & $\begin{array}{l}\text { Nap } \\
\text { Nap }\end{array}$ & $\overline{-}$ & \\
\hline 32. Debris... & Cirrhosis & $\mathbf{0}$ & $\begin{array}{l}\text { Heavy } \\
\text { Dan }\end{array}$ & $\bar{t}$ & \\
\hline 33. Lams.... & Eyperthyroidism & 0 & Bust & - & \\
\hline 34. Offel.... & Neuritis & $\mathbf{0}$ & Heavy - & - & \\
\hline
\end{tabular}

when injected intravenously in dogs with stimulated gastric pouches resulted in marked inhibition of pouch secretion and achlorhydria. Gastric juices from 6 of 34 patients, 18 per cent of the samples, not suffering from pernicious anemia or malignant neoplasms produced similar effects. While the incidence of gastric secretory depression is much greater in the former than the latter group, other possibilities must be considered before assuming that it is due to a factor preponderant in pernicious anemia gastric juice.

Age of the patient. No correlation between the age of the patient and depressing effects of the injected gastric juice was possible.

Temperature. The effect of temperature upon gastric secretion in the dogs has been discussed above and ruled out as a causative factor in the positive experiments obtained from injection of gastric juice from control or pernicious anemia patients. 
Blood pressure. It is conceivable that a marked splanchnic vasodilation would result first in a stimulation of gastric secretion and then if this persisted a reduction in secretion. Experiments were performed upon anesthetized dogs whose carotid arteries were cannulated to a manometer and blood pressure variations observed following intravenous injection of "positive" pernicious anemia juices, saliva from pernicious anemia patients, and control human gastric juices. A wide variation in effects upon blood pressure occurred, but it was clearly shown that the pernicious anemia gastric juices which produced marked inhibition of gastric secretion in dogs with gastric pouches did not produce significant blood pressure changes.

Carbon dioxide combining power of the blood. According to Browne and Vineberg (4) when the carbon dioxide combining power of the blood of dogs falls to 30 volumes per cent or less, gastric secretion is inhibited. In two dogs during achlorhydric periods resulting from injection of gastric juice from pernicious anemia patients, samples of blood withdrawn showed no reduction in $\mathrm{CO}_{2}$ combining power. When blood was withdrawn from dogs showing achlorhydria due to injection of enterogastrone (see below) the $\mathrm{CO}_{2}$ combining power was found not to be lowered when compared with samples withdrawn before the injection when acid juice was being secreted by the pouch.

Saliva. Saliva was collected from 5 of the patients with pernicious anemia whose gastric juices were tested above, by having them chew paraffin and expectorate into receptacles. Each of the samples was injected intravenously into a dog under the same conditions as in the injection of gastric juice, a total of 7 experiments being performed. In no instance was an achlorhydria produced. In 2 experiments the pouch secretion volume fell to 3 drops for one 10-minute period, 80 minutes after injection.

Enterogastrone. As stated above Ivy and Gray (1) and Kosaka and Lim (2) showed that intravenous injection of extracts of duodenal mucosae that have been in contact with fat depress gastric secretion in the dog. The factor, a chalone, responsible for this has been called enterogastrone. As far as the writers have been able to determine, no investigations have been previously reported in which gastric juice was examined for enterogastrone. In two experiments, the injection of an achlorhydric dog's pouch juice into other dogs failed to suppress secretion. The achlorhydric juice in these instances was obtained in one case as a result of induced hyperthermia and in the other it was obtained from a pouch which did not secrete acid although the dog was fed lean meat. In other dogs with achlorhydria due to injection of enterogastrone, insufficient quantities of the achlorhydric juice were obtained to perform injections in doses similar to those employed in the experiments with human juice. In a further attempt to obtain pouch juice that might contain a depressant, dogs were fed a small piece of lean meat and then at 10 to 20 -minute intervals they were fed raw and warmed suet, some of which was also triturated with olive oil. In this manner the gastric and duodenal mucosa were brought into contact with fat and conditions made favorable for generation of enterogastrone. Under these conditions the pouch secretions were less in volume than if the dogs had been fed lean meat. However, marked reduction in free acid titer of the juices was not regularly observed. Commencing one hour after the beginning of the fat feedings the samples of juice obtained during the next 2 to 3 hours were pooled, neutralized, and reinjected the following day into the dogs which, however, were now fed lean meat. Of 10 such experiments 8 were negative, 1 was considered a + experiment and 1 a ++ result. Comparing these results with the 12 negative control experiments of Group A, it was concluded that under the conditions of the experiments enterogastrone generated in a physiological manner might appear only in occasional instances in sufficient concentration in dogs' gastric juice to suppress gastric pouch secretion when the juice is injected in doses of $1 \mathrm{cc}$. of the "enterogastrone juice" per kilogram weight of the animal.

The question then arising is whether the gastric secretory depressant observed in the experiments with human juice might not be due to an abnormally large amount of enterogastrone. Against such an explanation is the fact that in the patients the gastric juice was collected in the morning after several hours starvation and upon histamine stimulation, and thus there was no opportunity for recent or prolonged contact of the duodenal mucosa with fat. This would favor the view that the secretory depressant in human gas- 
tric juices might be some factor other than enterogastrone, although of similar physiological action. On the other hand, the incidence of positive experiments among the controls is, in our opinion, too high to consider merely as "false positives" and would suggest that the gastric secretory depressant found apparently in relatively high concentration in pernicious anemia juice represents a marked increase of a factor that may be normally present in relatively low concentrations (enterogastrone?) in samples of gastric juice from patients not having pernicious anemia. The differentiation of enterogastrone from other possible secretory depressants in gastric juice will be dealt with in a subsequent publication. Furthermore, studies similar to those carried out above but with achlorhydric juices obtained from patients with gastric carcinoma and malignant neoplasms outside the stomach will also be reported.

\section{SUMMARY}

The gastric juices from 16 of 18 patients with pernicious anemia and achlorhydria, when injected intravenously into dogs with gastric pouches, the secretion of which had been stimulated by feeding, resulted in a transitory marked depression of the pouch secretion and achlorhydria (89 per cent of the samples). The injection of gastric juices from 34 hospitalized patients not having pernicious anemia or malignant neoplasms yielded similar gastric secretory inhibition in 6 instances (18 per cent of the samples). The secretory depressant effect of a sample of human gastric juice was abolished by boiling for 10 minutes.

The hypothesis that achlorhydria, in pernicious anemia at least, is associated with the presence of some gastric secretory inhibitor or to some profound distortion of normal hormonal control of gastric function is discussed.

\section{BIBLIOGRAPHY}

1. Ivy, A. C., and Gray, J. S., Enterogastrone. Published in Cold Spring Harbor Symposia on Quantitative Biology, 1937, 5, 405.

2. Kosaka, T., and Lim, R. K. S., Demonstration of the hormonal agent in fat inhibition of gastric secretion. Proc. Soc. Exper. Biol. and Med., 1930, 27, 890.

3. Vanzant, F. R., and Snell, A. M., The effect of nonspecific protein on the pain of ulcer and on gastric secretion. J. Clin. Invest., 1932, 11, 647.

4. Browne, J. S. L., and Vineberg, A. M., The interdependence of gastric secretion and the $\mathrm{CO}_{2}$ content of the blood. J. Physiol., 1932, 75, 345. 